\title{
Detecção de Helicobacter spp. em amostras de mucosa gástrica de cães assintomáticos e alterações histológicas associadas
}

\section{Identification of Helicobacter spp. in gastric mucosa samples asymptomatic dogs and associate histological alterations}

\section{Manuella Carvalho da COSTA ${ }^{1}$; Paulo Renato dos Santos COSTA ${ }^{2}$; João Carlos Pereira da SILVA Renner Emerson de Negreiros MAIA ${ }^{3}$; José do Carmo Lopes MOREIRA ${ }^{2}$}

${ }^{1}$ Departamento de Biologia Celular, Tecidual e do Desenvolvimento da

Universidade Federal de Alfenas, Alfenas - SP, Brasil

${ }^{2}$ Departamento de Veterinária da Universidade Federal Viçosa, Viçosa - SP, Brasil

${ }^{3}$ Médico Veterinário autônomo

\begin{abstract}
Resumo
O presente estudo teve por objetivo correlacionar o número de bactérias espiraladas e as alterações histológicas da mucosa gástrica em cães de vida livre. Foram analisadas biopsias gástricas endoscópicas de 28 cães assintomáticos. Para análise histológica, foi realizada avaliação qualitativa, onde foram atribuídos escores de 0 a 3, considerando a densidade de bactérias espiraladas por campo (400x), a presença de células inflamatórias, o número de agregados linfoides e a existência de alteração degenerativa glandular. A prevalência de Helicobacter spp, identificado pela histologia (Carbol-Fucscina) e positividade no teste da urease, foi de 100\%. Dos 28 cães, 18 (64,3\%) receberam escore 3 e 10 (35,7\%) o escore 2 para a densidade de bactérias. O infiltrado inflamatório predominantemente linfoplasmocitário foi de grau leve (escore 1) em 17 (60,7\%) cães e moderado em $6(21,4 \%)$ cães. Dos 28 cães, 14 (50\%) receberam escore 1 para degeneração glandular e $9(32,1 \%)$, o escore 0 . As regiões do corpo e antro apresentaram maior número de resultados positivos à histopatologia. Apesar do número elevado de bactérias encontrado nas amostras analisadas, as alterações histológicas foram classificadas como de grau leve na maioria dos animais. A presença do Helicobacter spp. não parece estar relacionado com sintomatologia de gastrite.
\end{abstract}

Palavras-chave: Helicobacter spp. Cães.Infiltrado inflamatório.

\begin{abstract}
The objective of the present study was to establish a relationship between the number of spiral bacteria and gastric mucosa histological alterations in mongrel dogs. Endoscopic biopsies of 28 asymptomatic dogs were analyzed. Qualitative evaluation was performed for histological analysis, in which scores from 0 to 3 were attributed, considering the density of spiral bacteria per field $(400 \mathrm{x})$, presence of inflammatory cells, number of lymphoid aggregates and existence of gland degenerative alteration. The prevalence of Helicobacter spp., identified by hystological technique (Carbol - fuchsine) and positive urease test, was100\%. Eighteen (64.3\%) of the 28 dogs presented score 3, and 10 $(35.7 \% 0)$, score 2 for the density of bacteria. The inflammatory infiltrate, predominantly lymphocytic, was slight (score 1 ) in $17 \mathrm{dogs}(60.7 \%)$ and moderate in $6(21.4 \%)$. From the 28 dogs, 14 (50\%) scored 1 for glandular degeneration and $9(32.1 \%)$ scored 0 . The body and antrum regions presented the highest positive result to histopathology. Despite the high number of bacteria found in the analyzed samples, the histological alterations have been classified as slight in most of the animals. The presence of Helicobacter spp. apparently does not produces gastritis symptoms.
\end{abstract}

Keywords: Helicobacter spp. Dogs. Inflammatory infiltrate.

\section{Introdução}

A presença de bactérias espiraladas no estômago de animais foi originalmente descrita há mais de 100 anos. Desde então, esses micro-organismos, inicialmente chamados espiroquetas, posteriormente organismos semelhantes ao Campylobacter e, atualmente, organismos semelhantes ao Helicobacter, têm sido re-

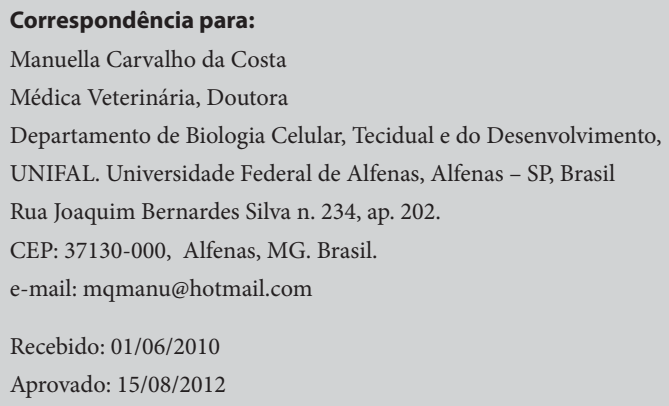


gularmente associados a exames gástricos e às vezes a lesões histopatológicas ${ }^{1,2}$. As espécies de Helicobacter são bactérias gram negativa com relativa capacidade de se multiplicar no estômago, graças à produção e importante atividade da enzima urease $\mathrm{e}^{3}$.

Ao contrário do que acontece com a infecção por H. pylori no homem, o significado da infecção por bactérias do gênero Helicobacter em cães ainda não está esclarecido, porque as mesmas têm sido estudadas em cães e gatos clinicamente sadios, bem como naqueles com sintomas gastrointestinais ${ }^{4}$. A alta prevalência destas bactérias sugere que as mesmas não apresentam potencial patogênico para os animais domésticos ${ }^{5}$.

Várias bactérias espiraladas foram identificadas e descritas em diferentes espécies animais incluindo cães, gatos, furões, porcos, bezerros, guepardos e várias espécies de macacos ${ }^{1,3}$.

Não foi observada correlação entre o grau de inflamação e o de colonização por Helicobacter ${ }^{6}$. Contudo, as alterações histológicas como inflamação, aglomerados linfoides e mudanças degenerativas nas células parietais, têm assumido um indicativo de patogenicidade das helicobactérias ${ }^{7}$. Entretanto, essas alterações têm sido observadas tanto em animais com sintomatologia gastrintestinal como em cães clinicamente saudáveis. Na realidade, a maioria dos estudos tem falhado em mostrar o significado clínico do Helicobacter em cães ${ }^{8}$.

Evidências consideram o potencial de alguns animais, principalmente os domésticos, serem a fonte da infecção zoonótica das Helicobactérias, já que micro-organismos com morfologias semelhantes ao $H$. felis e outros organismos semelhantes ao $H$. pylori foram observados no estômago de humanos com gastrite ${ }^{10}$.

O diagnóstico da infecção por organismos semelhantes ao Helicobacter pode ser realizado através de métodos invasivos, que requerem a realização de endoscopia para a coleta de fragmentos de mucosa gástrica e incluem o teste rápido de urease, citologia, histopatologia, cultura e $\mathrm{PCR}^{8,11}$.

Durante a avaliação histopatológica, pode ser observado o tipo e o número de infiltrado celular, onde predominam linfócitos, plasmócitos, células mononucleadas, eosinófilos e neutrófilos, além da presença de atrofia, hipertrofia, metaplasia, fibrose, edema e aglomerados linfoides ${ }^{9,12}$.

O presente estudo tem por objetivo correlacionar o número de bactérias espiraladas e as alterações histológicas da mucosa gástrica em cães assintomáticos.

\section{Material e Método}

Foram selecionados 28 cães adultos de vida livre, clinicamente sadios, sem raça definida, oito machos e 20 fêmeas, com peso variando entre 6 e $25 \mathrm{~kg}$, capturados pela Prefeitura Municipal de Viçosa e mantidos no canil experimental do Departamento de Veterinária (DVT) da Universidade Federal de Viçosa por um período de 30 dias. Durante o período experimental,os cães foram mantidos em baias coletivas com quatro animais em cada baia, onde receberam vermicida (Drontal Cães ${ }^{\circledR}$ Bayer S.A., São Paulo, Brasil), ectoparasiticida (Top-line ${ }^{\circledR}$ Merial Brasil, Campinas, Brasil) e ficaram em observação (quarentena) durante 15 dias. Os cães foram considerados clinicamente saudáveis por não apresentarem anormalidades no exame físico, hemograma e urinálise. Os animais foram mantidos no mesmo ambiente, onde receberam a mesma ração comercial para cães adultos (Kanina ${ }^{\circledR}$ Purina, São Paulo, Brasil) e água ad libidum.

Foram realizadas endoscopias e biópsias gástricas de todos os cães, submetidos previamente a um jejum sólido de 12 horas e hídrico de duas horas. Os animais receberam acepromazina a $1 \%$ (Acepran ${ }^{\circledR}$ Univet S.A., São Paulo, Brasil) como medicação pré-anestésica na 
dose de $0,1 \mathrm{mg} / \mathrm{kg}$ pela via intravenosa. Cerca de 10 minutos depois, a anestesia geral foi induzida com tiopental sódico (Thiopentax ${ }^{\circledR}$ Cristalia S. A., São Paulo, Brasil) na dose de $12,5 \mathrm{mg} / \mathrm{kg}$, por essa mesma via, para permitir a intubação endotraqueal e endoscopia. Após atingir o plano anestésico, caracterizado por movimentos respiratórios regulares e ausência de reflexos motores, foi iniciada a endoscopia e, posteriormente, as biópsias. A manutenção da anestesia foi realizada com dose suplementar do anestésico injetável, quando necessário.

Os animais foram posicionados em decúbito lateral esquerdo, possibilitando a introdução de um gastroscópio, modelo Olympus CV-1, com 9,5 mm de diâmetro. No intervalo entre a realização de cada procedimento, todo o equipamento e instrumental era esterilizado utilizando-se imersão em solução de glutaraldeído $2 \%$, evitando, desta forma, a transmissão de eventuais doenças pela forma iatrogênica, por meio do uso de endoscópios e sondas contaminados.

Nos cães utilizados no presente experimento e submetidos ao exame endoscópico do estômago, procederam-se os exames da integridade da mucosa, observando sua coloração, da presença de lesões pré-ulcerativas e/ou ulcerativas, de alterações circulatórias, da presença de parasitas e outras alterações em sua superfície.

Após a endoscopia, foram colhidos quatro fragmentos da mucosa gástrica, obedecendo a um mapeamento realizado previamente e correspondente a: dois fragmentos da região do corpo gástrico e dois fragmentos da região do antro gástrico. Esses fragmentos foram submetidos a exames citológicos, histopatológico e ao teste de urease.

Após a realização dos procedimentos descritos acima, os animais retornaram para as suas respectivas baias, onde permaneceram até o final do experimento.

Para o teste rápido de urease, foram colhidos fragmentos da mucosa da região do corpo gástrico que foram colocados em "kit" comercial, para detectar
Helicobacter pylori, contendo ureia e indicador de $\mathrm{pH}$ vermelho fenol. O teste era considerado positivo quando a solução adquiria uma coloração de tonalidade rosa, indicando presença da bactéria devido à liberação de amônia. Registra-se que o teste é baseado na produção de urease que hidrolisa a ureia em amônia, aumentando o pH local ${ }^{3,8,11}$. A reação foi considerada fortemente positiva naqueles casos em que a viragem do meio ocorreu entre uma e três horas, ou fracamente positiva nas amostras em que a reação ocorreu após quatro horas.

Os fragmentos de mucosa gástrica foram fixados em formol neutro tamponado a $10 \%$, por 24 horas, desidratados em concentrações crescentes de álcool, clareados em xilol e incluídos em parafina, seguindo-se a técnica preconizada para utilização na rotina em histopatologia.

Os cortes com espessura de $4 \mu \mathrm{m}$ foram corados e analisados em microscopia de luz, sendo os resultados expressos em diferentes graus, utilizando para tanto os seguintes parâmetros: infiltração inflamatória, degenerações glandulares, número de aglomerados linfoides e concentração de bactérias espiraladas, por campo microscópico de 400 vezes.

A coloração pela Carbol-Fucsina foi utilizada visando a identificação de bactérias espiraladas do gênero Helicobacter e a quantificação do grau de colonização.

A coloração pela Hematoxilina-Eosina (HE) foi usada para se realizar uma descrição histológica adequada, incluindo a identificação de eventuais alterações inflamatórias, a natureza e o número de infiltrado celular, degeneração glandular e a presença de aglomerados linfoides na mucosa gástrica. O grau de gastrite foi estimado com base na quantidade de infiltrado de linfócitos, plasmócitos ou polimorfonucleares na lâmina própria.

Após processamento e análise histológica e mensuração da densidade de bactérias, os resultados foram submetidos a procedimentos estatísticos, visando a comparação de médias por meio do Teste de Wilco- 
xon, ao nível de significância de 5\%, além do teste de Coeficiente de Correlação Pearson. Os dados obtidos no experimento foram processados, utilizando-se o sistema SAEG 4.0 (Sistema para análises estatísticas e genéticas).

Para análise histológica, foi realizada avaliação qualitativa, na qual foram atribuídos escores, considerando a densidade de bactérias espiraladas por campo (400x), a presença de células inflamatórias, o número de agregados linfoides e a existência de alterações degenerativas glandulares ${ }^{5,13}$, conforme o disposto no quadro 1.

\section{Resultados}

O teste da urease e o exame histopatológico revelaram a presença de Helicobacter em todos os cães. Durante a realização do teste de urease, houve variação no tempo de mudança de coloração do meio indicador. Em $28,57 \%$ das amostras, a mudança de coloração ocorreu após 4 horas (prova fracamente positiva) e, em $71,42 \%$ das amostras, a viragem do meio ocorreu em até três horas (prova fortemente positiva), indicando que todos os animais da amostra, embora com diferentes intensidades, conviviam com a bactéria.

Houve correlação positiva entre o teste de urease e a densidade de bactérias, revelando que quanto maior a densidade de bactérias nas regiões gástricas pesquisadas, maior a positividade do teste de urease.

O presente estudo não demonstrou a ocorrência de falsos positivos e de falsos negativos no teste de urease verificada por meio da correlação dos resultados deste teste com a visualização da bactéria nos fragmentos de mucosa corados pela Carbol-Fucsina.

As alterações mais frequentemente observadas ao exame histopatológico em cortes corados pela Hematoxilina-Eosina foram infiltrados celulares predominantemente de mononucleares (linfócitos e plasmócitos) presentes na grande maioria dos fragmentos de mucosa examinados, ocorrência de aglomerados linfoides, hiperemia e degenerações glandulares (Figura 2).

Os resultados que expressam todos os parâmetros analisados encontram-se na tabela 1 . Os infiltrados de células inflamatórias eram difusos, na maioria dos casos, e a maior fração das amostras apresentou leve infiltrado inflamatório (escore 1), ocorrendo predominantemente na região fúndica em relação à região antral. Apenas algumas amostras não apresentaram infiltrado inflamatório (escore 0) e nenhum animal apresentou exsudação celular em grau muito intenso (escore 3).

As degenerações glandulares, de pequena a média intensidade, ocorreram de forma equivalente nas

Quadro 1 - Escores de avaliação histopatológica da mucosa gástrica de acordo com a densidade de bactérias espiraladas, intensidade do infiltrado inflamatório, número de agregados linfoides e degenerações glandulares

\begin{tabular}{|c|c|c|c|c|}
\hline Escore & $\begin{array}{c}\text { Densidade } \\
\text { de Bactérias } \\
\text { Espiraladas }\end{array}$ & $\begin{array}{c}\text { Intensidade } \\
\text { do Infiltrado } \\
\text { Inflamatório }\end{array}$ & $\begin{array}{c}\text { Agregados } \\
\text { Linfoides }\end{array}$ & $\begin{array}{c}\text { Degenerações } \\
\text { Glandulares }\end{array}$ \\
\hline $\mathbf{0}$ & ausente & normal & nenhum & nenhuma \\
\hline $\mathbf{1}$ & leve & leve & 1 agregado & $\begin{array}{c}\text { menos do que 20\% } \\
\text { das glândulas com } \\
\text { degeneração }\end{array}$ \\
\hline $\mathbf{2}$ & moderada & moderada & 2 agregados & $\begin{array}{c}\text { de 20 a 50\% das } \\
\text { glândulas com } \\
\text { degeneração }\end{array}$ \\
\hline 3 & severa & severa & $\begin{array}{c}3 \text { ou mais } \\
\text { agregados }\end{array}$ & $\begin{array}{c}>50 \% \text { glândulas com } \\
\text { degeneração }\end{array}$ \\
\hline
\end{tabular}



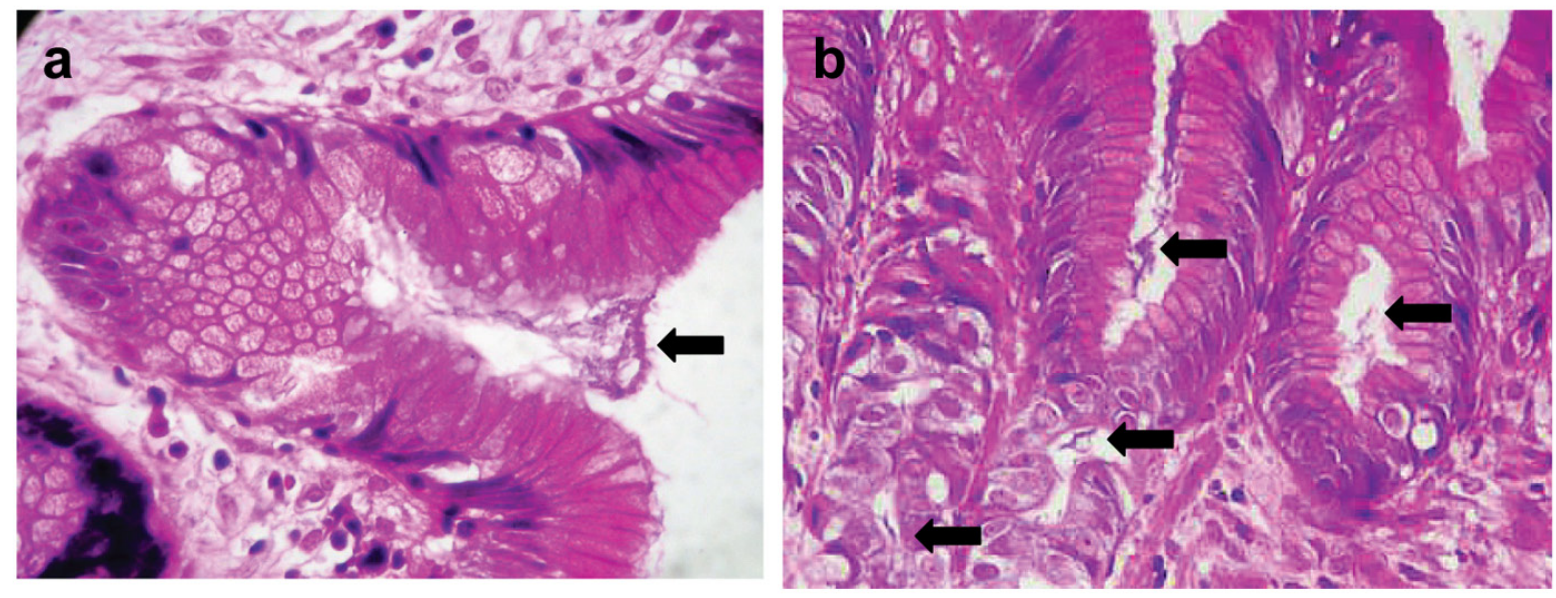

Figura 1 - Bactérias de forma espiralada (setas) sobre a camada epitelial de revestimento da mucosa (a) e no interior das glândulas gástricas (b) em um dos animais- (Carbol- Fucsina- $1000 \mathrm{X}$ )
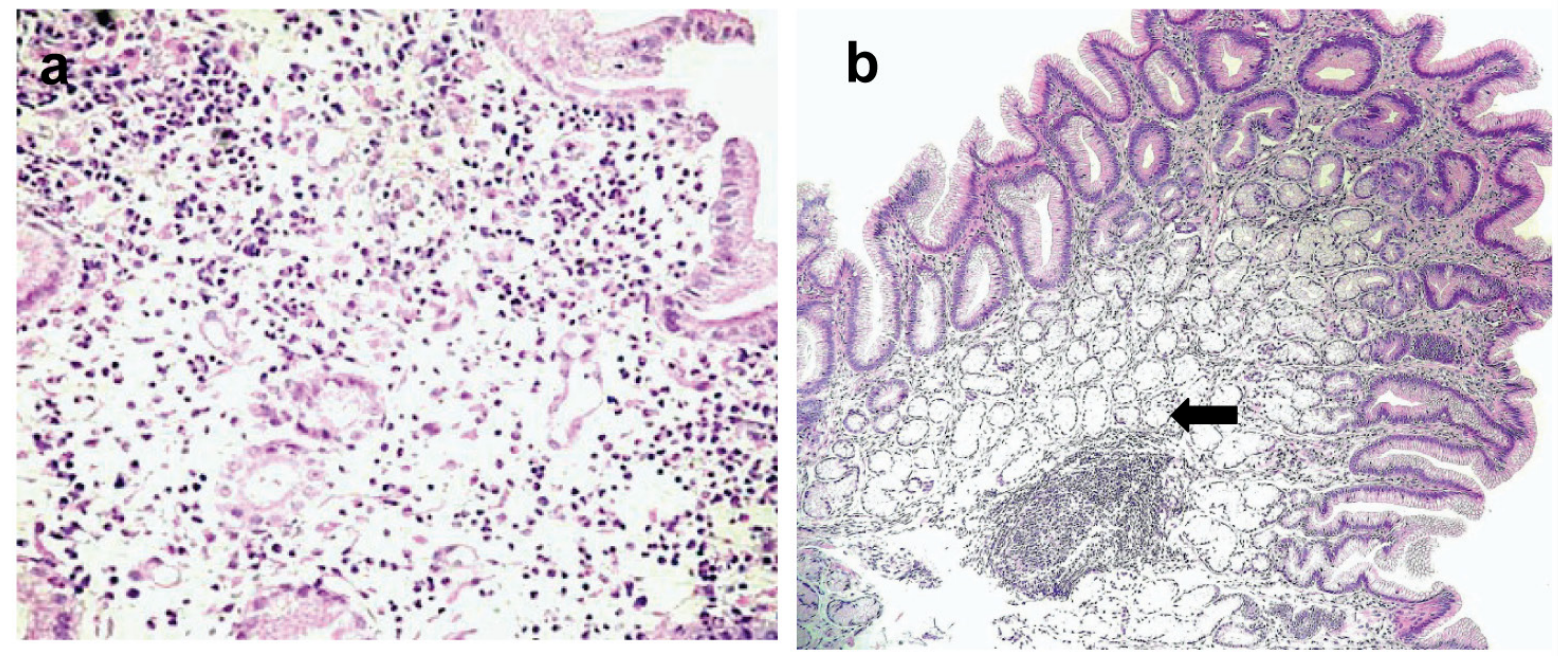

Figura 2 - Corte histológico de mucosa gástrica com infiltrado inflamatório linfoplasmocitário (escore 2) (a) e presença de aglomerado linfoide (b) no mesmo animal (H\&E - $200 \mathrm{X}$ e $100 \mathrm{X}$ ) (seta)

Tabela 1 - Porcentagem dos animais com o escore do grau de inflamação e grau de colonização de Helicobacter spp. das regiões do corpo e antro da mucosa gástrica (EI: escore de infiltrado inflamatório; AL: aglomerado linfoide; DG: degeneração glandular; EH: colonização por Helicobacter spp.)

\begin{tabular}{ccccccccc}
\hline & \multicolumn{4}{c}{ Grau de inflamação } & & \multicolumn{2}{c}{ Grau de colonização } \\
\cline { 2 - 9 } Escores & \multicolumn{3}{c}{ Região do Corpo } & \multicolumn{2}{c}{ Região do Antro } & \multicolumn{2}{c}{$\begin{array}{c}\text { Região } \\
\text { do Corpo do Antro }\end{array}$} \\
\cline { 2 - 9 } & EI & AL & DG & EI & AL & DG & HE & HE \\
\hline 0 & 17,8 & 57,1 & 32,1 & 25 & 92,8 & 39,2 & 0 & 0 \\
1 & 60,7 & 35,7 & 50 & 53,5 & 0 & 57,1 & 3,6 & 3,6 \\
2 & 21,4 & 7,1 & 17,8 & 21,4 & 3,6 & 3,6 & 35,7 & 32,1 \\
3 & 0 & 0 & 0 & 0 & 3,6 & 0 & 60,7 & 64,2 \\
\hline
\end{tabular}


duas regiões da mucosa gástrica que foram submetidas à análise. Já os aglomerados linfoides foram de menor ocorrência e se faziam mais frequentes na mucosa fúndica quando comparada à mucosa antral.

As preparações coradas pela Carbol-Fucsina permitiram a visualização das bactérias espiraladas, quantificadas nas regiões do corpo e antro gástrico. As bactérias possuíam coloração avermelhada e, em todos os casos, apresentavam-se grandes, alongadas, espiraladas, morfologicamente semelhantes ao Helicobacter heilmannii. Encontravam-se presentes, ora na superfície epitelial junto ao muco, ora nas criptas gástricas e ainda nas glândulas gástricas (Figura 1). Bactérias morfologicamente semelhantes ao $H$. pylori não foram observadas em nenhum animal.

\section{Discussão}

As alterações mais frequentemente observadas ao exame histopatológico em cortes corados pela Hematoxilina-Eosina foram infiltrados celulares predominantemente de mononucleares (linfócitos e plasmócitos) presentes na grande maioria dos fragmentos de mucosa examinados, ocorrência de aglomerados linfoides, hiperemia e degeneraçõesglandulares,conc ordando com o que foi estabelecido por alguns autores ${ }^{9,12,14,15}$, ao estudar a inflamação gástrica em cães.

Baseado nas características morfológicas da bactéria e devido ao fato do cão ser hospedeiro primário dessa espécie, suspeita-seque no presente estudo houve predominância do Helicobacter heilmannii. Morfologicamente, é possível estabelecer diferenças entre as bactérias espiraladas que colonizam o estômago do cão ou do homem, consistindo em diferença básica o fato do $H$. heilmannii ser mais espiralado do que o $H$. pylori ${ }^{5,16,17,18}$.

A análise histopatológica das biópsias gástricas coradas pela Carbol-Fucsina revelou a presença da bactéria em todos os animais (100\%), o que de certa forma, condiz com os dados reportados na literatura que relatam a colonização de cães com Helicobacter variando de 61 a 100\% dos animais, independentemente do estado clínico dos mesmos ${ }^{2,8,14,15,19}$. Este índice pode chegar a $100 \%$ em animais que vivem coletivamente, como em canil ${ }^{11}$. Deve ser reafirmado que, no presente experimento, todos os animais utilizados eram provenientes do canil experimental do Departamento de Veterinária da Universidade Federal de Viçosa.

Além dessas observações, a literatura indica que a existência de bactérias espiraladas na mucosa gástrica de cães pode não estar correlacionada com doenças digestivas do animal, podendo, por outro lado, se constituir em fonte de disseminação dessas bactérias $^{1,6,8}$.

As bactérias foram encontradas principalmente no lúmen das glândulas gástricas, nas fossetas gástricas e no muco adjacente ao epitélio. Neste contexto, foi observado uma maior prevalência de bactérias no lúmen das glândulas gástricas, podendo também ser encontradas nas células parietais e glândulas gástri$\operatorname{cas}^{5,20}$. A presença da bactéria variou de acordo com a região do estômago estudada, registrando índices de $64,28 \%$ na região do antro e $60,71 \%$ na região do corpo, discordando de alguns autores ${ }^{4,5}$, que afirmam que a região do cárdia, fundo e corpo são mais comumente colonizadas que a região do antro.

Houve correlação positiva entre o teste de urease e a densidade de bactérias, revelando que quanto maior a densidade de bactérias nas regiões gástricas pesquisadas, maior a positividade do teste de urease. O teste da urease é utilizado para determinar a produção dessa enzima pela bactéria, visto que esta substância pode ser produzida em grande quantidade por esse micro-organismo, podendo fornecer resultado positivo em menos de uma hora ${ }^{3}$. De forma que a sensibilidade do teste é de apenas 70 a $90 \%$. Por outro lado, discordando do autor citado anteriormente, a alta sensibilidade e especificidade do teste de urease, pode variar de $88-100 \%{ }^{6}$, o que secomprovou no presente estudo, em 
que todas as amostras gástricas apresentaram resultado positivo no teste de urease, e, ao exame histopatológico, foram visualizadas bactérias com características morfológicas semelhantes ao Helicobacter.

Reações falso-negativas podem ocorrer após o tratamento de gastrite devido ao baixo número de bactérias e, por outro lado, o falso-positivo pode resultar do aumento de $\mathrm{pH}$ devido à contaminação da amostra com sangue e a outras bactérias produtoras de urease como o Proteus mirabilis e Pseudomonas aeruginosa, além de bactérias da cavidade oral ${ }^{6,7}$. Contudo, no presente estudo, não ficou demonstrada a presença de reações falso-positivas e ou falso-negativas no teste de urease, uma vez que se pode relacionar a reatividade desse teste com a visualização da bactéria por meio da histopatologia com a coloração pela Carbol-Fucsina.

O exame histológico convencional, com o método de coloração pela hematoxilina-eosina, permite identificar a bactéria quando a sua densidade de colonização for alta. Para esse fim, o método histoquí-

\section{Referências}

1.HAESEBROUCK, F.; PASMANS, F.; FLAHOU, B.; CHIERS, K.; BAELE, M.; MEYNS, T.; DECOSTERE, A.; DUCATELLE, R. Gastric Helicobacters in domestic animals and nonhuman primates and their significance for human health. Clinical Microbiology Review, v. 22, n.2, p. 202-23,2009.

2.BAILLON, M. L.; MARSHALL-JONES, Z. Bactérias enteropatogênicas em cães e gatos. Waltham Focus, Ed. Esp. p. 12-18, 2004.

3. BELLI, C. B.; FERNANDES, W. R.; SILVA, L. C. L. C. Teste de urease positivo em eqüino com úlcera gástrica - Helicobacter sp.? Arquivos do Instituto Biológico, v. 70, n. 1, p. 17-20, 2003.

4. YAMASAKI, K.; SUEMATSU, H.; TAKAHASHI, T. Comparison of gastric lesions in dogs and cats with and without gastric spiral organism. Journal of American Veterinary Medical Association, v. 212, n. $4,529-533,1998$.

5. SIMPSON, K. W.; MCDONOUGH, P. L.; STRAUSS-AYALI, D.; CHANG, Y. F.; HARPENDING, P.; VALENTINE, B. A. Helicobacter felis infection in dogs: effect on gastric structure and function. Veterinary Pathology, v. 36, n. 1, p. 237-248, 1999.

6. FLATLAND, B. Helicobacter infection in humans and animals. Compendium on Continuing Education for the Practicing Veterinarian, v. 24, n. 9, p. 688-697, 2002.

7.HAPPONEN, I.; LINDEN, J.; SAARI, S.; KARJALAINEN, M.; HANNINEN, M. L.; JALAVA, K.; WESTERMARCK, E. Detection and effects of helicobacters in healthy dogs and dogs with signs of mico pela técnica de Carbol-fucsina é recomendado por ser uma técnica de baixo custo operacional e fácil execução. Além disso, esse método de coloração permite, além da detecção da bactéria, a possibilidade de identificar a espécie visualizada ${ }^{6}$.

\section{Conclusões}

No presente trabalho, todos os cães avaliados apresentaram resultados positivos para Helicobacter no teste rápido de urease, bem como na avaliação histopatológica realizada em fragmentos de mucosa corados pela Carbol-Fucsina, estando as bactérias distribuídas em todas as regiões examinadas. Ao exame histopatológico, a maior parte das amostras apresentou infiltrado inflamatório leve (escore 1) e densidade severa de Helicobacter spp (escore 3). Grande atenção deve ser dada a esses resultados em relação à saúde pública. Deve-se considerar a possibilidade dos cães servirem como reservatório para a transmissão de helicobactérias para os humanos.

gastrites. Journal of American Veterinary Medical Association, $v$. 231, n.12, p. 1767-1774, 1998.

8. ARAÚJO, I.C.; FERREIRA, A.M. Infecção por Helicobacter spp. em gatos: revisão. Clínica Veterinária, v. 7, n.37, p. 41-50, 2002.

9. SHABESTARI, A. S.; MOHAMMADI, M.; JAMSHIDI, S.; SASANI, F; BAHADORI, A.; OGHALAIE, A. Assessment of chronic gastritis in pet dog and its relation with helicobacterlike organisms. Pakistan Journal of Biology Science, v. 11, n. 11, p. 1443-1448, 2008.

10. HANDT, L. K.; FOX, J. G.; STALIS, I. H.; RUFO, R.;LEE, G.; LINN, J.; LI, X.; KLEANTHOUS, H. Characterization of feline Helicobacter pylori strains and associated gastritis in a colony of domestic cats. Journal of Clinical Microbiology, v.33, n. 9, p.2280-2289, 1995

11. NEIGER, R.; DIETERICH, C.; BURNENS, A.; WALDVOGEL, A.; CORTHÉSY-THELA, I.; HALTER, F.; LAUTERBURG, B.; SCHMASSMANN, A. Detection and prevalence of Helicobacter infection in pet cats. Journal of Clinical Microbiology, v. 36, n. 3, p. 634-637, 1998.

12. WIINBERG, B.; SPOHR, A.; DIETZ, H. H.; EGELUND, T.; GREITER-WILKE, A.; MCDONOUGH, S. P.; OLSEN, J.; PRIESTNALL, S.; CHANG, Y. F.; SIMPSON, K.W. Quantitative analysis of inflammatory and immune responses in dogs with gastritis and their relationship to Helicobacter spp. infection. Journal of Veterinary Internal Medicine, v. 19, n. 1, p. 4-14, 2005 
13. IIMURO, M.; SHIBATA, H.; KAWAMORI, T.; MATSUMOTO, T.; ARAKAWA, T.; SUGIMURA, T.; WAKABAYASHI, K. Suppressive effects of garlic extract on Helicobacter pyloriinduced gastritis in Mongolian gerbils. Cancer Letters, v. 187, n. $1-2$, p. $61-68,2002$.

14. JENKINS, C. C.; BASSET, J. R. Helicobacter infection. Compendium on Continuing Education for the Practicing Veterinarian, v. 19, n. 3, p. 267- 279, 1997.

15. STRAUSS-AYALI, D.; SIMPSON, K. W. Gastric Helicobacter infection in dogs. Veterinary Clinical of North American: Small Animal Pratice, v. 29, n. 2, p. 397- 414, 1996.

16. EATON, K. A.; DEWHIRST, F. E.; PASTER, B. J.; TZELLAS, N.; COLEMAN, B. E.; PAOLA, J.; SHERDING, R. Prevalence and varieties of Helicobacter species in dogs from random sources and pets dogs: animal and public health implications. Journal of Clinical Microbiology, v. 34, n. 12, p. 3165-3170, 1996.
17. SIMPSON, K. W.; BURROWS, C. F. Gastritis, ulcers and Helicobacter spp. in humans, dogs and cats. Waltham Focus, v. 1, n. 7, p. 2-6, 1997.

18. KATO, S.; OZAWA, K.; SEKINE, H.; OHYAUCHI, M.; SHIMOSEGAWA, T.; MINOUR, T.; INUMA, K. Helicobacter heilmannii infection in a child after succesful eradication of Helicobacter pylori: case report and review of literature. Journal of Gastroenterolgy, v. 40, n. 1, p. 94-97, 2004.

19. NEIGER, R.; SIMPSON, K. W. Helicobacter infection in dogs and cats: facts and fictions. Journal of Veterinary Internal Medicine, v. 14, n. 2, p. 125-133, 2000.

20. VIEIRA, F. T. Freqüência e distribuição de Helicobacter ssp. na mucosa gástrica de cães. 2004. 60 p. Tese de (Doutorado Magister Scientiae) - Universidade Federal de Viçosa,Viçosa, 2004. 